\title{
Percutaneous lung abscess drainage: revisiting the old gold standard
}

\author{
Alessandro Matarese ${ }^{1}$, Mario Tamburrini², Unnati Desai ${ }^{3}$, Umberto Zuccon² \\ ${ }^{1}$ Department of Clinical Medicine and Surgery, Section of Respiratory Disease, University Federico II, Monaldi \\ Hospital, Naples, Italy; ${ }^{2}$ Interventional Pulmonologist, AAS5 Friuli Occidentale, Pordenone, Italy; ${ }^{3}$ Department of \\ Pulmonary Medicine, TNMC \& BYL Nair Hospital, Mumbai, India
}

\begin{abstract}
Lung abscess is defined as the necrosis of lung tissue with cavity formation due to varied etiology. The treatment of lung abscesses is medical involving antibiotics and chest physiotherapy. The failure of medical line of management requires an invasive surgical or percutaneous approach for drainage and control of infection. While the literature is ample regarding the surgical approach, it is rather scarce on the percutaneous approach. The percutaneous drainage has
\end{abstract}

Correspondence: Dr. Mario Tamburrini, Interventional Pulmonologist, AAS5 Friuli Occidentale, Pordenone, Italy.

Tel. +39.349.0091667.

E-mail: mario.tamburrini@aas5.sanita.fvg.it

Key words: Ultrasound guidance; fluoroscopy guidance; pigtail catheter; lung abscess.

Contributions: MT, UZ, AM patient management; UD, literature search, manuscript drafting. All the authors made a substantive intellectual contribution. All the authors have read and approved the final version of the manuscript and agreed to be accountable for all aspects of the work.

Funding: The authors do not have specific grant for this research from any funding agency in the public, commercial or not-for-profit sectors.

Conflict of interests: The authors declare that they have no competing interests, and all authors confirm accuracy.

Availability of data and materials: The data that support the findings of this study are available from the corresponding author upon reasonable request.

Ethics approval and consent to participate: This research was conducted in accordance with all relevant guidelines and procedures.

Consent for publication: The manuscript does not contain any individual person's data in any form.

Received for publication: 17 December 2019.

Accepted for publication: 17 February 2020.

${ }^{\circ}$ Copyright: the Author(s), 2020

Licensee PAGEPress, Italy

Monaldi Archives for Chest Disease 2020; 90:1214

doi: 10.4081/monaldi.2020.1214

This article is distributed under the terms of the Creative Commons Attribution Noncommercial License (by-nc 4.0) which permits any noncommercial use, distribution, and reproduction in any medium, provided the original author(s) and source are credited. been most studied with computed tomography guidance. With our case series we describe to the treatment of lung abscesses nonresponsive to medical management, by a bedside minimally invasive ultrasound or fluoroscopy guided percutaneous drainage approach.

\section{Introduction}

Pulmonary endocavitary percutaneous aspiration was first described by Monaldi in 1938. It was one of the cornerstones of tuberculosis treatment in the pre-antibiotic era. The same author applied this method to pyogenic lung abscesses thus becoming a valid therapeutic option even with this etiology [1]. Following the everincreasing availability of antibiotic therapy, the treatment of lung abscesses has become almost exclusively medical and conservative with a success rate close to $90 \%$ of cases [2-4]. The failure of medical treatment is due to multiple causes requiring an invasive surgical (usually lobectomy) or percutaneous approach [5-7]. There is vast literature on the surgical management in these scenarios. However rather scarce, only a few hundred cases describe the percutaneous drainage in lung abscess to our knowledge [8]. Although percutaneous drainage has advantages, it is not a very widespread method due to the potential complications. The aim of the present work is to describe our experience in the treatment of non-responsive lung abscesses by medical therapy using a minimally invasive percutaneous ultrasound-guided drainage with bedside approach.

\section{Case Series}

We retrospectively reviewed consecutive cases from two tertiary care referral hospitals centers in Italy from May 2018 to May 2019. We treated eight patients with lung abscess in this time period. All subjects had been treated with at least 2 weeks of antibiotic therapy either empirical or based on microbiological reports of sputum/tracheal aspirate. One patient was under immunosuppressive therapy which was discontinued at ward admission (Patient 8: steroids). Despite the medical treatment the clinical situations which we considered valid indications to proceed to percutaneous drainage were persistence of fever, lack of radiological resolution of the pulmonary pattern and presence of abscess collection $>4 \mathrm{~cm}$ in diameter (short axis). The techniques used were the following, almost similar to each other: two patients underwent percutaneous ultrasound assisted drainage by extemporaneous aspiration with kit from thoracentesis using a $14 \mathrm{G}$ needle (Macropharm Srl, Caltanissetta, Italy). The patients were positioned in the most ipsilateral (best) decubitus position. The collection was identified by ultrasound guidance and nearest cutaneous landmark marked. A 
sterile field was set up, without changing the patient's decubitus position. After adequate local anesthesia with $2 \%$ lidocaine, percutaneous aspiration of the purulent pulmonary collection was done. The remaining six patients were analogously evaluated by ultrasounds, the best decubitus (prone or on the healthy side) selected. After preparation of a sterile field and local anesthesia, the procedure was performed under direct ultrasound guidance, using the Seldinger technique with pig tail $14 \mathrm{~F}$ guided endocavitary drainage (modified Wayne pneumothorax set, Cook medical). We preferred this device because in our opinion is more accurate in placement and minimally traumatic. In two cases (Patient 3, Patient 4) the pigtail was inserted under additional fluoroscopy guidance. The clinical, radiological details of patients are given in Table 1.

Most responded to this approach. Figures 1 and 2 illustrate images in two of our patients. In two cases the isolation of the pathogenic organism from abscess drained pus (Patient 5, Streptococcus constellatus, Prevotella; Patient 6: Parvimonas micra) determined antibiotic therapy modification and resolution after 2 weeks treatment period. In the other cases antibiotic treatment was stopped the same day of drainage removal if there were clinical and radiological resolution. The only recorded complication occurred in patient 8 who developed pneumothorax after repositioning of intralesional drainage. This complication required the placement of a second pleural drain to treat pneumothorax which resolved subsequently (Figure 3) without empyema development.

\section{Discussion}

Lung abscess are formed due to liquefactive necrosis of the lung tissue, leading to formation of cavities (more than $2 \mathrm{~cm}$ ) containing necrotic debris or fluid caused by microbial infection. Lung abscess is primary when it results from existing lung parenchymal process and is secondary when it complicates another process, e.g. vascular emboli, bronchogenic cancer or follows rupture of extrapulmonary abscess into lung [8]. The treatment of lung abscesses has become almost exclusively medical and conservative. The antibiotic therapy is required for 4 to 6 weeks and adjusted as per the susceptibility reports of the organism isolated [2-4]. The failure of medical treatment is usually attributable to the virulence of the pathogen and / or failure to achieve an adequate concentration of the drug at the level of the lesion. Other causes of failure to resolve are the presence of other underlying lung diseases and reduced lung compliance [5-7]. Failure of medical treatment involves the need to resort to an invasive surgical (usually lobectomy) or percutaneous approach. Although percutaneous drainage has advantages as the initial treatment modality for complicated pulmonary abscesses, to date it remains not a very widespread method due to the potential complications mainly related to the trocar approach, especially to the radiologists who perform it mainly under guidance of computed tomography and less frequently under fluoroscopic guidance.

The medical treatment fails if the patient had risk factors like a large abscess cavity ( $>6 \mathrm{~cm}$ ), compromised immunity, neoplasm, advanced age, reduced level of consciousness or infection with certain aerobic pathogens (Klebsiella pneumoniae, Pseudomonas aeruginosa, Staphylococcus aureus). Ten to $20 \%$ of patients with lung abscesses eventually required surgical or percutaneous drainage due to medical treatment failure. Surgery was associated with high morbidity and mortality. The success rate of computed tomography guided drainage of lung abscess has been reported up to $90 \%$ [9]. Yellin et al. reported the routine use of percutaneous

Table 1. Characteristics of lung abscess patients.

\begin{tabular}{|c|c|c|c|c|c|c|c|c|}
\hline Patient & 1 & 2 & 3 & 4 & 5 & 6 & 7 & 8 \\
\hline Age (years) & 64 & 47 & 61 & 72 & 31 & 43 & 63 & 49 \\
\hline Gender & Male & Male & Male & Female & Male & Male & Male & Female \\
\hline Comorbidities & Schizophrenia & Glioblastoma & H1N1 infection & $\begin{array}{c}\text { Cancer, } \\
\text { atrial fibrillation }\end{array}$ & None & None & $\begin{array}{l}\text { Diabetes } \\
\text { mellitus }\end{array}$ & $\begin{array}{l}\text { Wegener } \\
\text { granulo- } \\
\text { matosis }\end{array}$ \\
\hline Site of lung abscess & RLL & RLL & RLL & LLL & RLL & RLL & RLL & LUL-LLL \\
\hline Antibiotics & PTZ & $\begin{array}{l}\text { PTZ, LNZ, } \\
\text { CPX }\end{array}$ & $\begin{array}{l}\text { OTV, AMC, } \\
\text { CFS, MPM }\end{array}$ & VRZ & $\begin{array}{l}\text { PTZ, LNZ, } \\
\text { CTM, CDM, } \\
\text { TCP }\end{array}$ & $\begin{array}{l}\text { MPM, LNZ, } \\
\text { CDM, VRZ }\end{array}$ & PTZ, LFX & $\begin{array}{c}\text { MPM, LNZ, } \\
\text { APB, TCP }\end{array}$ \\
\hline Antibiotic treatment period & 3 weeks & 3 weeks & 2 weeks & 3 weeks & 2 weeks & 4weeks & 4 weeks & 2 weeks \\
\hline Microbiology & Negative & $\begin{array}{c}\text { B: } \\
\text { Salmonella } \\
\text { typhi, } \\
\text { Moraxella } \\
\text { catarrhalis }\end{array}$ & $\begin{array}{c}\text { t.a.: } \\
\text { Achromobacter } \\
\text { xylosoxidans. } \\
\text { Pus: } \\
\text { Bacteroides }\end{array}$ & $\begin{array}{c}\text { Bal: } \\
\text { Aspergillus }\end{array}$ & $\begin{array}{c}\text { Pus: } \\
\text { Streptococcus } \\
\text { constellatus, } \\
\text { Prevotella }\end{array}$ & $\begin{array}{c}\text { Pus: } \\
\text { Prevotella }\end{array}$ & Negative & Negative \\
\hline Pigtail & Yes & Yes & Yes & Yes & No & No & Yes & Yes \\
\hline Time drainage stay & 8 days & 10 days & 3 days & 10 days & & & 10 days & 5 days \\
\hline Fluoroscopy (F) / USG (U) guided & $\mathrm{U}$ & $\mathrm{U}$ & $\mathrm{F} ; \mathrm{U}$ & $\mathrm{F} ; \mathrm{U}$ & $\mathrm{U}$ & U & $\mathrm{U}$ & U \\
\hline Clinical improvement & Yes & Yes & Yes & Yes & Yes & Yes & Yes & No \\
\hline Radiological resolution & Complete & Complete & Partial & Near complete & Complete & Near Complete & Complete & No \\
\hline Complication & No & No & No & No & No & No & No & PNX \\
\hline
\end{tabular}

B, blood; t.a., tracheal aspirate; PTZ, Piperacillin-Tazobactum; LNZ, Linezolid; CPX, Ciprofloxacin; OTV, Oseltamivir; AMC, Amoxycillin-clavilulinic acid; LFX, Levofloxacin; CFS, cephalosporin; MPM, Meropenam; APB, Amphotericin B; TCP, Teicoplanin; VRZ, Voriconazole; CDM, Clindamycin; CTM, Clarithromycin; PNX, pneumothorax. 
drainage in 48 patients with a lung abscess in whom medical therapy failed with good success rate and infrequent complications. They used chest-X ray postero-anterior and lateral views to determine the site of drainage. They used three types of drainage devices: an Argyle trocar catheter, a Foley catheter, and a 12-gauge intravenous polyethylene catheter [10]. Subsequently, Rice et al. described tube drainage and Crouch et al. and Parker et colleagues described use of small-bore catheters in lung abscess drainage [11-13]. Ha et al. described percutaneous catheter drainage of lung abscess using computed tomography and fluoroscopy guidance [14]. Computed tomography guided percutaneous drainage in 40 cases was described by Kelogrigoris et al. [15].

In concurrence with the available literature, our experience about percutaneous drainage of pyogenic lung abscesses was safe and effective. We used two different techniques because at the moment of clinical presentation in patients 5 and 6 pigtail catheters were not available in the institution. However we recognize to drainage of lung abscess by extemporaneous aspiration mainly a diagnostic value while endocavitary permanent drainage could be a real definitive treatment. Indeed for pigtail patients mean antibiotic treatment period post procedure were shorter ( 7 vs 14 days).
Literature also describes a different combined approach of using a double-lumen catheter for initial drainage and keeping it in situ for further lavage with saline and drainage at the same time [8] but the authors have not experience with this device.

In our series there was only one therapeutic failure in patient 8 mostly due to the associated Wegner's granulomatosis. Literature has rare reports of ultrasound or fluoroscopy guidance used in real time for drainage of lung abscess. We describe the same with our case series. The advantage of using pigtail drainage are numerous. It allows adequate complete drainage in lung abscess that is resistant to medical line of management. The pigtail insertion is by Seldinger technique allowing the wire to be positioned with great precision. Saline / antibiotic lavage can also be done using similar double lumen catheters. The advantage of our approach (both ultrasound and fluoroscopy guided) is the real time visualization of the catheter or needle while insertion over the computed tomography method avoiding complications. In addition bed side use of ultrasound or fluoroscope obviates the need for shifting the patient for procedures. Ultrasound can be safely used in most scenarios and situations and is a very portable tool. Fluoroscopy also similarly aids bedside intervention in these cases in the intervention pulmonology suite.
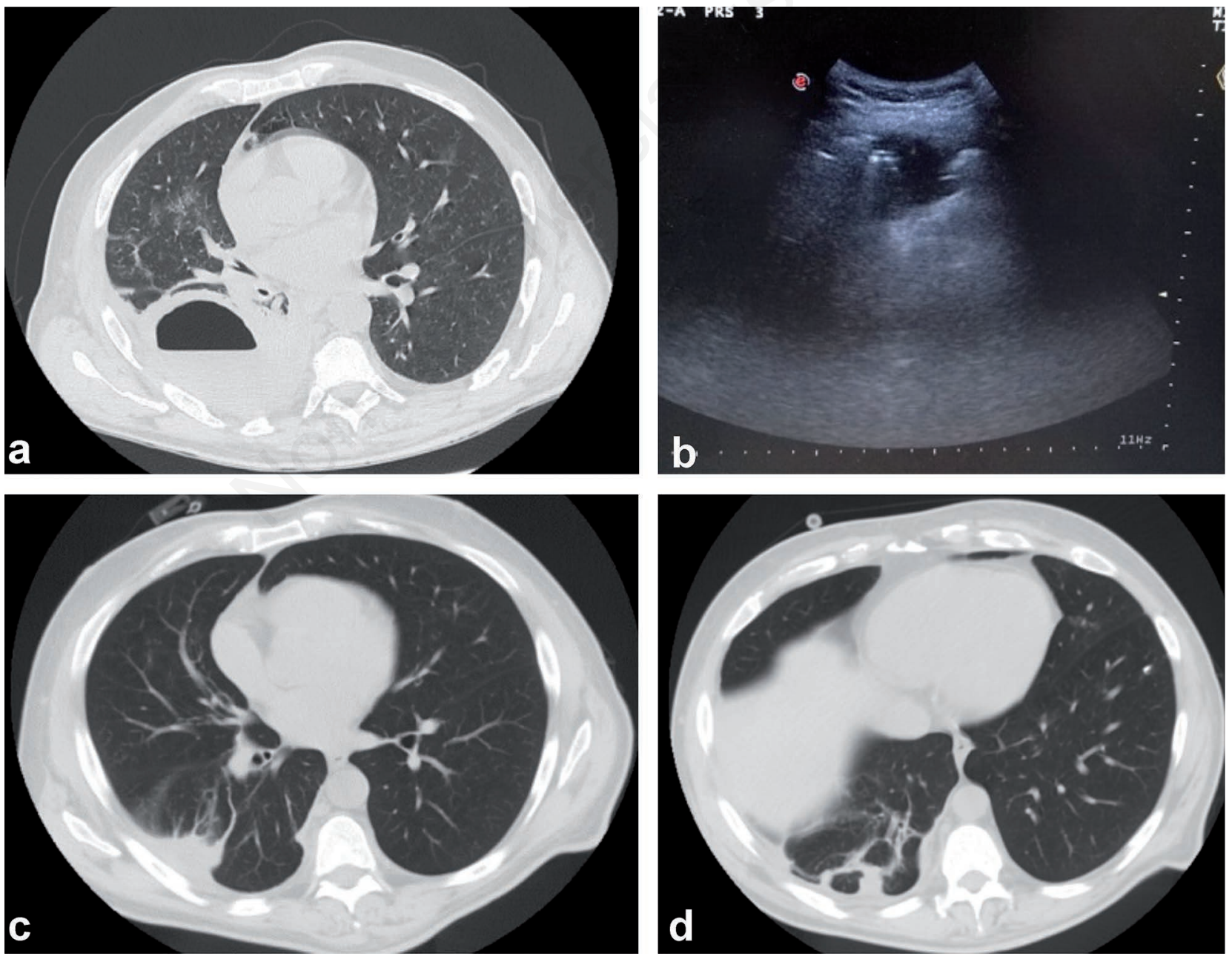

Figure 1. Patient 6: CT image prior to pigtail insertion (a); ultrasound image at the time of the procedure (b); CT image post pigtail guided aspiration and medical therapy $(c, d)$. 

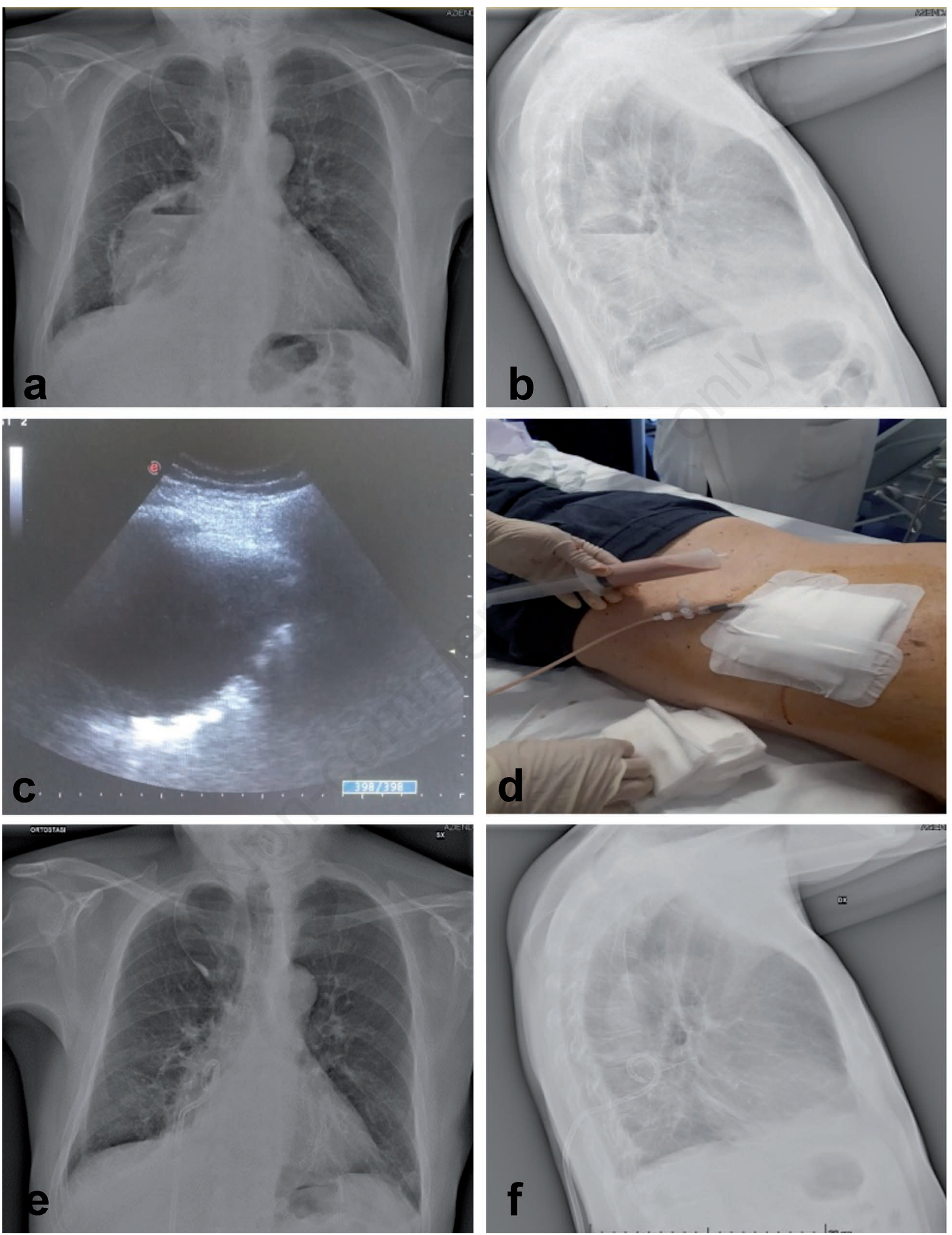

Figure 2. Patient 7: CXR baseline (a,b); preprocedural ultrasound image and image of drainage at the end of same (c,d); CXR after 5 days $(\mathrm{e}, \mathrm{f})$. 

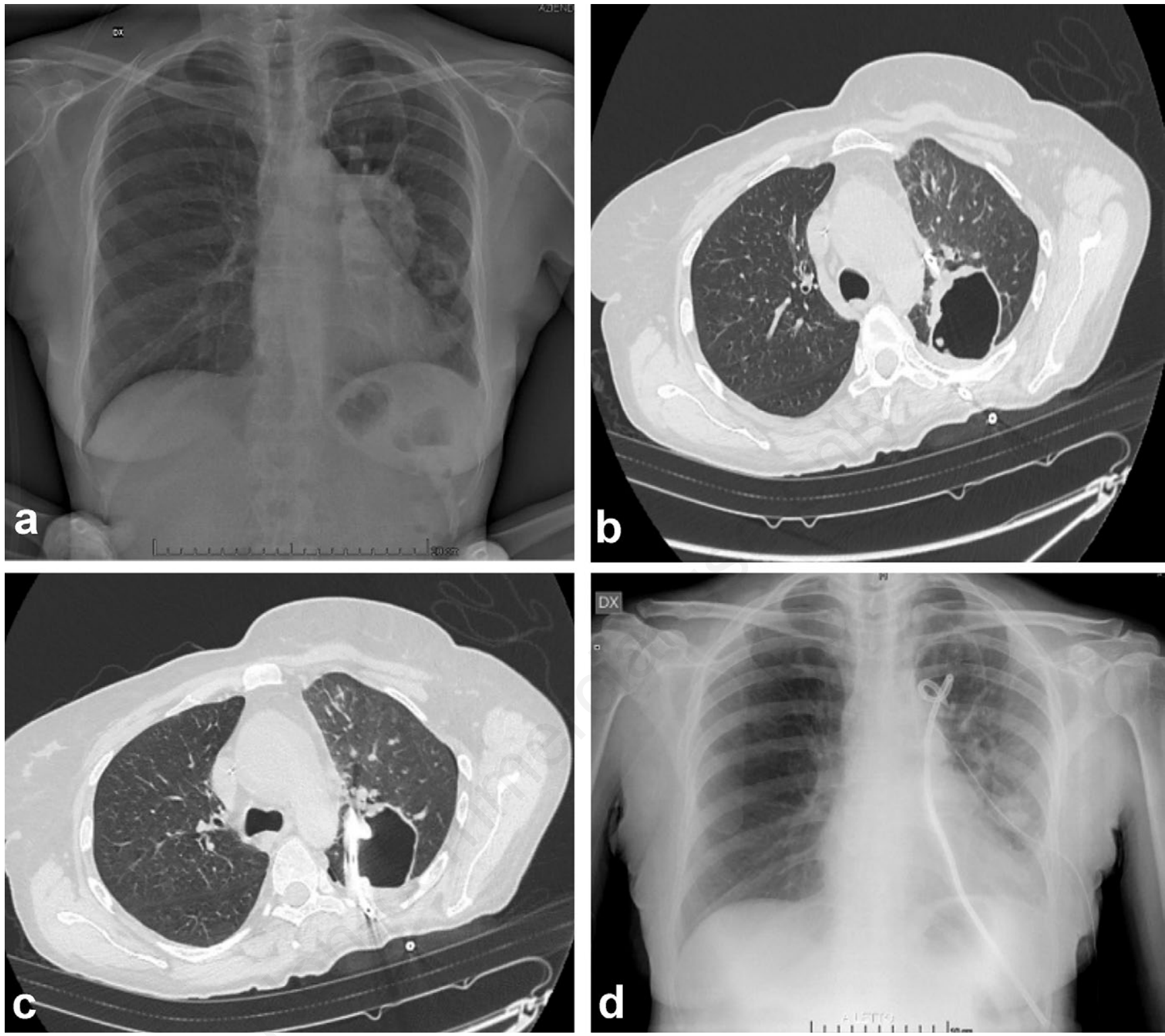

Figure 3. Patient 8: CXR baseline (a); CT thorax after pigtail positioning, note the intralesional drainage tangent to the medial wall of the abscess but with the distal end entering parenchyma (b,c); CXR after second drain placement due to emergence of massive pneumothorax in urgency $(\mathbf{d})$.

\section{References}

1. Monaldi V. Endocavitary aspiration in the treatment of lung abscess. Dis Chest 1956;29:193-201.

2. Neuthof H, Touroff ASW. Acute putrid abscess of the lung. Hyperacute variety. J Thorac Surg 1942;12:98-106.

3. Shim C, Santas GH, Zelefsky M. Percutaneous drainage of lung abscess. Lung 1990;168:201-7.

4. Klein JS, Schultz S, Heffner JE. Interventional radiology for the chest: imaging-guided percutaneous drainage of epidural effusions, lung abscess, and pneumothorax. AJR Am J Roentgenol 1995;165:581-8.

5. Vainrub B, Musher DM, Guinn GA, et al. Percutaneous drainage of lung abscess. Am Rev Respir 1978; 117: 153-60.

6. Mwandumba HC, Beeching NJ. Pyogenic lung infection. Factors for predicting clinical outcome of lung abscess \& thoracic empyema. Curr Opin Pulm Med 2000;6:234-9.

7. Hirshberg B, Sklair-Levi M, Nir-Paz R, et al. Factors predicting mortality of patients with lung abscess. Chest 1999;115:747-50.

8. Wali SO. An update on the drainage of pyogenic lung abscesses. Ann Thorac Med 2012;7:3-7. 
9. Yu H. Management of pleural effusion, empyema and lung abscess. Semin Intervent Radiol 2011;28:75-86.

10. Yellin A, Yellin EO, Lieberman Y. Percutaneous tube drainage: The treatment of choice for refractory lung abscess. Ann Thorac Surg 1985;39:266-70.

11. Rice TW, Ginsberg RJ, Todd TRJ. Tube drainage of lung abscesses. Ann Thorac Surg 1987;44:356-9.

12. Crouch JD, Keagy BA, Delany DJ. Pigtail catheter drainage in thoracic surgery. Am Rev Respir Dis 1987; 36:174-5.
13. Parker LA, Melton JW, Delany DD, Yankaskas BC. Percutaneous small bore catheter drainage in management of lung abscess. Chest 1987;92:213-8.

14. Ha HK, Kang MW, Park JM, et al. Lung abscess-percutaneous catheter therapy. Acta Radiola 1993;34:362-5.

15. Kelogrigoris M, Tsagouli P, Stathopoulos K, et al. CT-guided percutaneous drainage of lung abscesses: review of 40 cases. JBR-BTR 2011;94:191-5. 